\title{
Response to a Research Article Entitled: Prevalence of Lactose Intolerance and its Association with Malnutrition in Children
}

\section{Dear Editor,}

With clearly outlined prospects for research, I congratulate Dr. Neel Kanth and colleagues for their interesting study on the "Prevalence of lactose intolerance and its association with malnutrition in children", published in a recent issue of the National Journal of Health Sciences (NJHS, Volume 4, Issue 3, 2019) [1]. The high prevalence of lactose intolerance documented by the authors is confirmed by a recent meta-analysis, which found a lactose malabsorption among adults and children aged 10 years or older of $58 \%$ in Pakistan [2]. The 2018 Pakistan National Nutrition Survey also showed that $40.2 \%$ children were stunned, $28.9 \%$ were underweight, and $17.7 \%$ were wasted [3]. The authors rightly pointed out that further research is urgently needed to better understand the association of lactose intolerance and malnutrition in children [1]. However, in my opinion, here are two aspects worth mentioning.

Firstly, current references to the subject are missing from this research article. The two most recent studies of the 20 references are from 2006 and 2001. All other papers used are over 20 years old [1]. It is not entirely understandable why the authors did not incorporate more recent reviews (such as from Hirani 2012; Hegar, et al. 2015; Grenov, et al. 2016 or Asim, et al. 2018) or original studies (such as Abuhamdah, et al. 2013) into their discussion [4-8]. I am surprised that this was not criticized in the peer review process.

Secondly, there are some mistakes in the discussion section. For example, the authors name studies on lactose intolerance in children by Yang, et al. in China and Sadre, et al. in Iran [9, 10], but do not list them in the references section. Instead, incorrect reference numbers can be found in the corresponding text passages [1]. Kanth and colleagues also quote "Abrunmer RJ. In Netherlands where they found that lactose intolerance does not always present with symptoms", this work also does not appear in the references section [1]. In my literature research in PubMed and Google Scholar I could not find any contributions from Abrunmer RJ. I assume that other NJHS readers would also like to know the reference to this study. There are also several spelling mistakes in the discussion section for quoted author names. For example: Bejanones is written for Bujanover, Beheiry is written for El-Beheiry (an incorrect reference number is also given here: 11 instead of 20), Boeyee is written for Boey, Herman is written for Hermans, Tendon is written for Tandon.

I think this otherwise very good study by Kanth, et al. can be strengthened by additional discussion [1].

\section{CONFLICT OF INTEREST}

Declared none.

\section{ACKNOWLEDGEMENTS}

Declared none.

\section{REFERENCES}

[1] Kanth N, Neel S, Santosh R, Abbasi, Z. Prevalence of lactose intolerance and its association with malnutrition in children. Natl J Health Sci 2019; 4(3): 103-9.

DOI: $10.21089 /$ njhs. 43.0103

[2] Storhaug CL, Fosse SK, Fadnes LT. Country, regional, and global estimates for lactose malabsorption in adults: A systematic review and meta-analysis. Lancet Gastroenterol Hepatol 2017; 2(10): 738-46. DOI: 10.1016/S2468-1253(17)30154-1

[3] Ministry of National Services Regulation and Coordination, Government of Pakistan, UNICEF Pakistan. Pakistan National Nutrition Survey 2018. 2019;

Available at: https://www.unicef.org/pakistan/media/1951/file/Final\%20Key\%20Findings\%20Report\%202019.pdf [Accessed 16 March 2020].

[4] Hirani SA. Malnutrition in young Pakistani children. J Ayub Med Coll Abbottabad 2012; 24(2): 150-53.

[5] Hegar B, Widodo A. Lactose intolerance in Indonesian children. Asia Pac J Clin Nutr 2015; 24 (Suppl 1): S31-40. DOI:10.6133/apjcn.2015.24.s1.06

[6] Grenov B, Briend A, Sangild PT, et al. Undernourished Children and Milk Lactose. Food Nutr Bull 2016; 37(1): 85-99. DOI:10.1177/0379572116629024

[7] Asim M, Nawaz Y. Child Malnutrition in Pakistan: Evidence from Literature. Children (Basel) 2018; 5(5): 60. DOI:10.3390/children5050060

[8] Abuhamdah SMA, Oriquat GA, Saleem TH, Hassan MH. Prevalence of lactose intolerance in primary school children in Qena Governorate, Egypt. Jordan J of Biol Sci 2013; 6(4): $334-6$.

[9] Yang Y, He M, Cui H, Bian L, Wang Z. The prevalence of lactase deficiency and lactose intolerance in Chinese children of different ages. Chin Med J (Engl) 2000; 113(12): 1129-32.

[10] Sadre M, Karbasi K. Lactose intolerance in Iran. Am J Clin Nutr 1979; 32(9): 1948-54. DOI: 10.1093/ajcn/32.9.1948

Martin Hofmeister*

*Department Food and Nutrition, Consumer Centre of the German Federal State of Bavaria, Munich, Germany. E-mail: hofmeister@vzbayern.de 


\section{AUTHOR'S REPLY}

Thank you for your appreciation. Here, I am addressing your concern:

1. This research was conducted around 8 years back, by that time whatever data we had available and had access to we tried to mention that.
2. About the "typos" in the discussion part we apologise for that and take the joint responsibility of myself and the peer reviewers. We make sure to get it fixed.

*Sejal Neel

* Sindh Government Children Hospital, North Nazimabad, Karachi, Pakistan.

E-mail: sejal.neel@hotmail.com
Dates for Letter to Editor:

Received: March 17, 2020

Approved: May 15, 2020

(C) 2020 National Journal of Health Sciences.

This is an open-access article.
Dates for Response to Letter:

Received: May 06, 2020

Approved: May 15, 2020 